\title{
Whales and Whaling
}

\section{International Conference}

$\mathrm{U}$ NTIL some ten years ago, modern whaling was conducted almost entirely from land stations, and the most important centres of the industry were in British territorial waters where suitable regulations could be enforced. The development of the modern factory ship led to a great expansion of the industry in the form of unrestricted whaling on the high seas, and the operations extended over a vast area in the Antarctic. The Governments of those nations most interested in whaling realized that unlimited hunting must eventually cause depletion of the stock and the collapse of the industry. An International Conference was therefore held in June 1937, and an agreement was signed by representatives of the Union of South Africa, the United States of America, the Argentine, Australia, Germany, the United Kingdom, the Irish Free State, New Zealand and Norway. By the terms of this agreement, measures were taken for the restriction of whaling, including the imposition of a minimum size limit for various species, the limitation of the Antarctic whaling season to three months, and, with minor reservations, the prohibition of pelagic whaling north of $40^{\circ} \mathrm{S}$.

In accordance with the recommendations of last year's Conference, a second Conference was held on June 14-24 last. The purpose of this Conference was to invite the adherence of other countries which had not yet acceded to the previous convention, to examine the results of the new regulations and to consider what further measures might be applied. The following Governments sent delegates : Union of South Africa, United States of America, Argentine, Australia, Canada, Denmark, Eire, France, Germany, United Kingdom, Japan, New Zealand and Norway. An observer also attended on behalf of the Portuguese Government, and the interests of Newfoundland were watched by the United Kingdom delegation.

The Conference noted that although the provisions of the 1937 agreement had limited the scope of Antarctic whaling, it had not succeeded in checking the number of whales killed. Indeed it appears that the number of whales taken in the 1937-38 season was approximately 44,000, which is about 10,000 in excess of the figures for the previous season. This is partly attributable perhaps to the high price of whale oil last year. Had it not been for the agreement of 1937, a still larger number of whales would no doubt have been taken.
The new measures agreed to in this year's Conference are embodied in a protocol which amends the existing agreement, and the discussions and recommendations of the Conference are reported upon in a final Act. The following are among the articles in the protocol.

Factory ships are prohibited from taking Humpback whales anywhere south of $40^{\circ} \mathrm{S}$. for a period of a year. There is evidence that the stock of Humpbacks stands in even greater danger than that of Blue whales, and the Conference considered a proposal for the world-wide protection of this species for a year. Agreement to this could not be reached, since many land stations are largely dependent on Humpbacks. Protection in Antarctic waters, however, is expected to save large numbers.

Pelagic whaling is now totally prohibited in the Pacific sector of the Antarctic, south of $40^{\circ} \mathrm{S}$. and between $70^{\circ} \mathrm{W}$. and $160^{\circ} \mathrm{W}$. This applies in the first instance for a period of two years. Although whaling has not so far spread to these waters, it is known that the number of whales there is sufficient to be worth protecting. Practical difficulties militate against the imposition of such a sanctuary in the established whaling grounds, but the new measure may at least act as a check on future expansion.

The open season of three months in the Antarctic remains unchanged, as do the minimum size limits for the various species, but small concessions in size limits have been made for land stations where the whale meat is used as food for local consumption.

The other articles of the protocol include a clearer definition of a land station (a point which provoked much discussion over the status of factory ships working in territorial waters) and minor amendments to some articles in the principal agreement.

The Conference considered a resolution of the Whaling Committee of the International Council for the Exploration of the Sea in the following terms: "The Committee, viewing with alarm the evident decline of the stock of Blue whales, is of opinion that nothing less than limitation of the total amount of whale oil which may be taken in any whaling season can be effective in preserving the stock of the whales from being reduced to the level at which it can no longer be the object of economic exploitation". It was felt, however, that at the present stage it would be impossible to 
reach agreement to such a measure, which would involve fixing a global quota each year and arranging to cease all whaling when the quota was reached.

Proposals for limiting the number of catchers attached to each expedition and for limiting the oil production of each factory ship were also abandoned on account of the difficulty of apportioning such restrictions equitably among the various expeditions.

It will be seen then that the new measures agreed upon do not go very far, but the first object of the Conference, which was to secure the prolongation of the existing agreement and the adhesion of additional Governments, has been achieved. The principal agreement has been ratified by the Governments of Eire, Germany, Norway, New Zealand, United Kingdom and United States of America, whilst Canada and Mexico have since acceded to it. The Argentine is enforcing the principal agreement by executive decree, and formal ratification is only a matter of time. It is understood that ratification by Australia and South Africa has been delayed only by constitutional difficulties, and the accession of France and Denmark is expected to follow. The Japanese delegation informed the Conference that its Government was prepared to take steps to accede after the interval of a year, and to observe the principles of the agreement as nearly as possible in the meantime. This undertaking of the Japanese is regarded as of great importance, since that nation is now operating on a large and increasing scale in the Antarctic.

In the final Act it is recommended among other things that the Governments and the whaling enterprises concerned should do their best to encourage the development of whale-marking as practised by the Discovery Committee.

The question of holding a future conference is recommended for consideration in the light of developments.

N. A. M.

\section{Obituary Notices}

Dr. W. W. Campbell, For. Mem. R.S.

$\mathrm{B}^{\mathrm{x}}$ the death on June 14 of W. W. Campbell, following that of G. E. Hale, American science has suffered the loss of another astronomer who was also a foreign member of the Royal Society.

William Wallace Campbell was born and bred on a farm in Ohio, the date of his birth being 1862 . He graduated in the University of Michigan in 1886, and the soundness of the academic training which he had then received is sufficiently attested by the nature of his later career. A year or two were then spent as professor of mathematics in the University of Colorado, after which he returned to the University of Michigan as instructor in astronomy. In 1891 Campbell joined the Lick Observatory as astronomer. The rest of his active life was connected for forty years with that institution and with the University of California. Retirement came in 1930, and before his death he had made his home in San Francisco.

Campbell became acting director of the Observatory on the death of Keeler, and the appointment was definitely confirmed in the following year (1901). He had in an eminent degree that combination of qualities which is necessary for success in the head of a great observatory in an isolated situation, and in this capacity he had the valuable support of his wife, Elizabeth Ballard Thompson, whom he married in 1892. There were three sons of this marriage, all surviving. He was also fortunate in finding a problem peculiarly adapted to his powers. Keeler, before turning to his classical researches on the nebulæ, had pushed the study of the radial velocity of the brightest stars as far as was practicable by visual means.
Further progress required the introduction of photographic methods. The circumstances on Mount Hamilton were exceptionally favourable, but the technical problems involved in avoiding the effects of flexure and maintaining uniform temperature had to be solved by original devices. Campbell developed great skill in dealing with the optical and mechanical problems thus presented, and in the Mills spectrograph he achieved a classical design. Chiefly by this instrument in conjunction with the Lick refractor, the radial velocities of all the brighter stars within the reach of the Observatory were determined with high accuracy in the course of a few years. To com. plete this new chapter in astronomy, by extending the work to the whole sky, an expedition was equipped and established at Santiago in Chile. The effectiveness of this branch from its beginning, at first under the leadership of Mr. W. H. Wright, is a proof that the success of Campbell's plans was by no means dependent on the famous Lick telescope.

The Lick Observatory, though it possesses a splendid equipment, is generously maintained as a department of the State university, but it has no endowment. For all the expenses of the branch in Chile and the cost of additional instruments as the need arose, Campbell had to rely largely on the generosity of wealthy friends of the Observatory, among whom the late Mr. D. O. Mills and Mr. W. H. Crocker may be specially mentioned. His conspicuous tact and persuasive qualities were clearly shown in gaining this necessary financial support.

Eclipse expeditions occupied much of Campbell's time and thought. In all, he took part in seven: 